\title{
INFLUENCE PARAMETERS ON TOOL DEFLECTIONS IN ROLL FORMING
}

\section{Martin Leonhartsberger, Matthias Lamprecht \& Friedrich Bleicher}
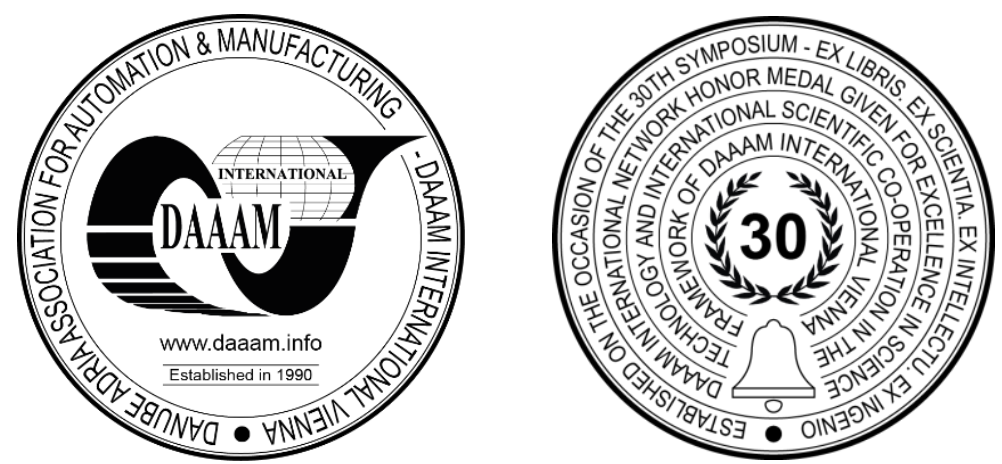

This Publication has to be referred as: Leonhartsberger, M[artin]; Lamprecht, M[atthias] \& Bleicher, F[riedrich] (2020). Influence Parameters on Tool Deflections in Roll Forming, Proceedings of the 31st DAAAM International Symposium, pp.0701-0707, B. Katalinic (Ed.), Published by DAAAM International, ISBN 978-3-902734-29-7, ISSN 1726-9679, Vienna, Austria

DOI: $10.2507 / 31$ st.daaam.proceedings.097

\begin{abstract}
In this paper, the compliant behaviour of a conventional setup of a roll forming mill is examined. On such a mill, few parts significantly contribute to the deflection of the tools when a strip of metal is transported and deformed. A major impact originates of the shafts with strung rolls. The rolls are changed in case a modified profile geometry is produced. This leads to varying properties of the setup through changing rolls and changing assembly parameters. The identification and understanding of the main impact factors on the stiffness of this assembly is crucial to ensure constant properties when disassembled and assembled again. The roll set, the axial preload and the feather key position are assumed to have the biggest impacts. These parameters are varied in a set of experiments to gather data to evaluate the significance of these impact factors. In the experiments the setup is burdened with a process-like load. Deflections and loads are measured and recorded simultaneously. The collected data sheds light on the main impact factors on the deflections, which are the roll set and the axial preload. These factors should deviate as little as possible from the first assembling to following assembling procedures of the identical roll set to ensure the same force-deflection behaviour of the whole setup. The data is then used to generate a nonlinear regression model to show that the used parameters are sufficient to describe the deflection behaviour of a roll forming mill.
\end{abstract}

Keywords: roll forming; bending; machine tool; measurement; tool deflection

\section{Introduction}

Roll forming is a continuous bending process, where an infeeding metal sheet is formed incrementally through contoured forming rolls at room temperature without changing the thickness of the material [1]. These rolls occur in pairs of horizontally arranged assemblies - the forming passes. These consecutively arranged forming passes gradually form the final profile shape. The process is highly productive for manufacturing profile shaped mass products. The range of applications of roll formed profiles is nearly endless. From automotive and construction industry over agriculture and environmental technology to the transportation and industrial engineering sector. As mentioned, the process is effective in mass production, but when it comes to increased demanded flexibility and lower quantities, roll forming has some disadvantages and other manufacturing methods are preferred. One of the big disadvantages is the high setup time for a changed profile geometry at the production line. Roll sets, for producing the desired profile, are aligned on shafts. 
The rolls need to be set up in the right position, relative to each other and relative to the next as well as the prior forming pass, to ensure exact profile dimensions and to prevent forming defects in the process [2]. In order to compensate in-process deflections during production already in the setup process, offside the production plant, it is of high interest to predict the deflection of the shafts with equipped rolls under realistic loads. The shafts, equipped with rolls, are the most compliant components of conventional forming mills [3]. In consequence, time intense and worker's experience depending fine adjustments at the production line can be reduced, which leads to less machine downtime [4]. In [3] and [5] the tool stiffness in simulations is considered by simple linear springs. This implementation lacks in accuracy when it comes to asymmetric profiles geometries and therefore an asymmetric force distribution between the operator- and drivesided forming stand. To predict the deflections, a more detailed understanding of the behaviour is required. The generated knowledge can be used to build up a model of the machinery for simulations and improvements of the setup. In roll forming, the deflection of the setup is of high interest when it comes to changing properties of the processed material. An increase in strength or thickness of the material changes the arising forces in the roll forming process, which leads to increased deflections of the shafts. These variations may cause geometric changes of the produced profile. In the worst case the profile does not meet the set geometric tolerances anymore. In order to simulate such geometric deviations due to varying material properties, the tool stiffness has to be represented in an accurate way. Although similar mechanical designs are common in different fields of engineering (e.g. gears, drive shafts), they mostly differ substantially from the current problem. And therefore, also studies about this kind of setup are rare. In [6] the deflection of stepped shafts is investigated and a simple model approach is established to calculate their deflection. The setup used in this paper is similar to a stepped shaft, but differs in the presence of more than one loaded part. Radi et al. [7] presents a mathematic modelling of a shaft-hub press fit. Such a fit behaves significantly different than a loose fit, which is present between the rolls and the shaft of a roll forming mill. An investigation of a shaft supported on both ends with strung rolls that are not press fitted, axially burdened with a preload and forced to bend as in the current focus, has not been found in literature. Gotlih et al. [8] investigated the stiffness behaviour of an industrial robot to build a simulation model. This is similar to the presented approach where the stiffness behaviour of a roll forming mill is studied to understand its characteristics and to build up a model for their force-deflection behaviour. Recent studies [9] focused on the shafts of such a mill and it was shown that the shafts without roll sets can be modelled by beam models with nonlinear springs. Another work [10] did research on the compliance of roll forming stands and how to reproduce a functional setup. Based on the gained knowledge, this paper concentrates on the identification of the significant parameters that may vary the mechanical characteristics of a shaft with strung rolls as used reality.

\section{Materials and methodology}

This paper presents an empirical approach to study the mentioned load-deflection behaviour. The loads are being induced by manual infeed of the upper against the lower roll set. Vertically arranged probes (TESA GT62 DC) in discrete positions acquire the deflections of the forming rolls (see Fig. 1 (1)). Force sensors (Kistler 9333A), which are installed in the forming stands, measure the generated load (2). The axial preload on the rolls and the shaft is detected by a strain gauge-based sensor system (3).The data is acquired by a DAQ-system (National Instruments 9205). The sampling frequency for all experiments is set to $50 \mathrm{~Hz}$. The roll sets are held in position by an axial preload, which is induced by a nut at the end of the shaft (see Fig. 1 left). This creates an axial compression force between the rolls and causes tensile stress in the shaft. To reveal the influence of the preload, six different levels are investigated (see Table 1). Previous studies showed that these are realistic values for the occurring preloads in the process, as the nuts are tightened by pneumatic impact wrenches, which are dependent on the handling, type of the wrench and the actual pressure in the pneumatic system.
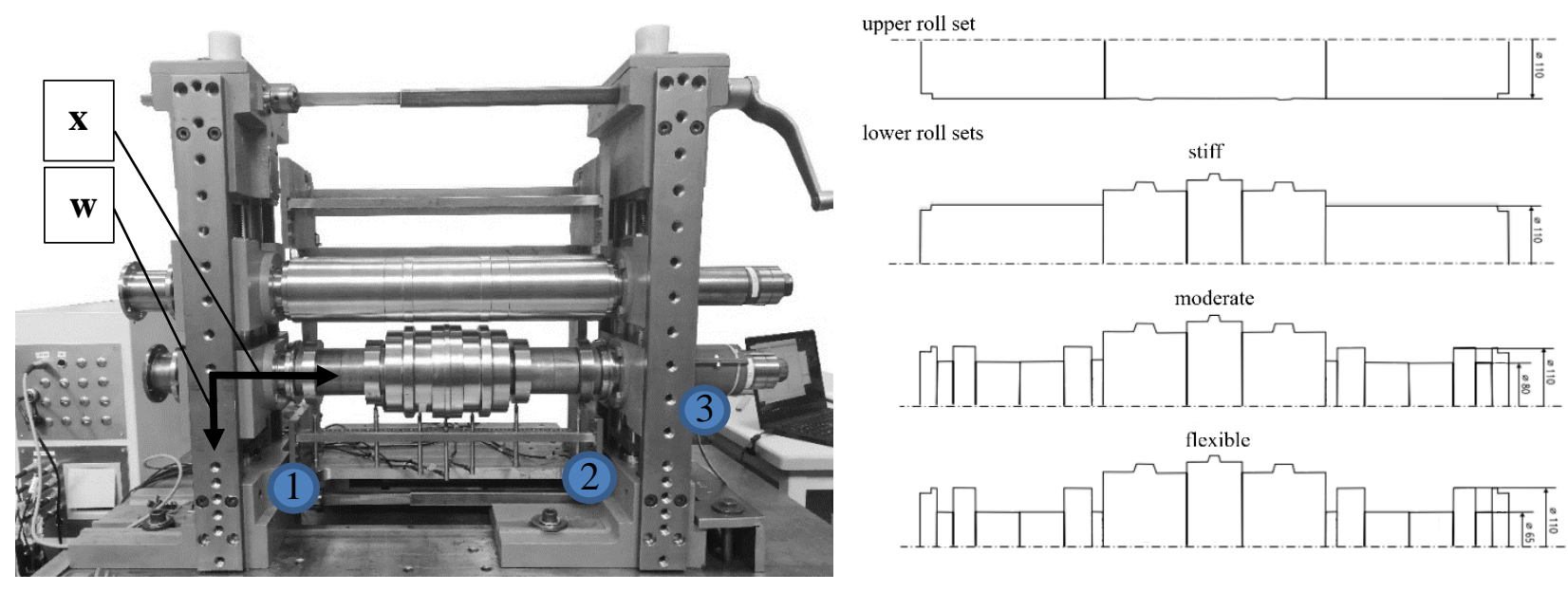

lower roll sets
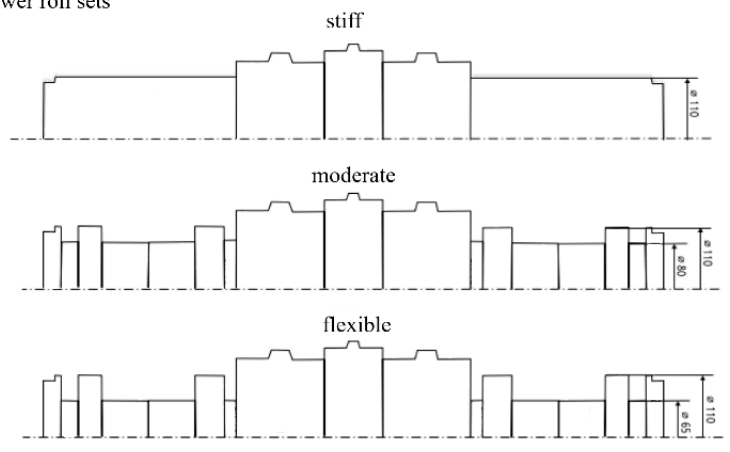

Fig. 1. Experimental setup and contour lines of the used roll sets 


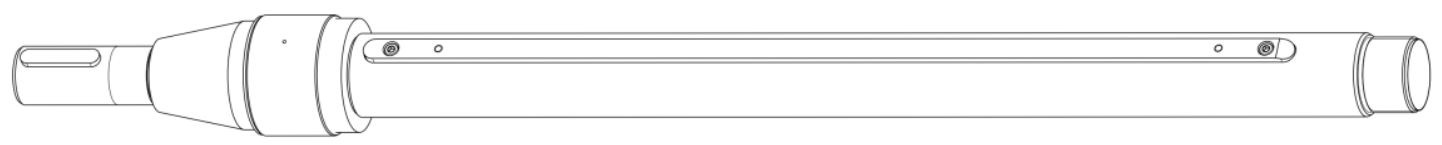

Fig. 2. Shaft with feather key

The rolls are connected to the shaft by a feather key (Fig. 2). The key itself, as well as the groove in the shaft, are also impact factors on the resilience of the system. Therefore, the angular key-position is also varied: horizontal, vertical in the compression zone and vertical in the tension zone. To represent the maximum variation of forming rolls, three different roll sets are studied (Fig. 1 right). One roll set being rather stiff (large diameters, wide rolls, small clearance between rolls and shaft) and one being relatively flexible (small diameters, many individual short rolls, small clearance between rolls and shaft). The third roll sets' geometric characteristics are somewhere in between the others. This roll set is called moderate and has nearly the same rolls than the flexible one but has a few rolls with bigger outer diameter and tighter geometric tolerances to the shaft. To generate reliable data, every experiment is repeated five times. The upper roll set is identical in all experiments (Fig. 1 right). All other parts including the shafts and the forming stands stayed identical in the experiments. The individual parameters which were varied and the chosen gradations are represented in Table 1 . The experiments are carried out full factorial.

\begin{tabular}{|c|c|c|}
\hline Key position & Roll set & Axial preload [kN] \\
\hline Horizontal (H) & Flexible & 20 \\
\hline Vertical compression (VC) & Moderate & 40 \\
\hline Vertical tension (VT) & Stiff & 60 \\
\hline & & 80 \\
\hline & & 100 \\
\hline & & 120 \\
\hline
\end{tabular}

Table 1. Table of Variations

The collected data is used to generate a regression model. Based on this model, it is presented that the used parameters are sufficient to describe the deflection behaviour of a roll forming mill.

\section{Results}

The measured data is presented in Fig. 3 to Fig. 5. The abscissa represents the x-position (see Fig. 1). The ordinate plots the deflections measured on the rolls. These diagrams present the deflections at a certain load level. The deflection of the forming stands is compensated in all data shown in the following figures. This leads to "pure data" of the deflections of the shafts equipped with forming rolls. An exemplary maximum external load of $20 \mathrm{kN}$ is used, because it represents often occurring forming forces.

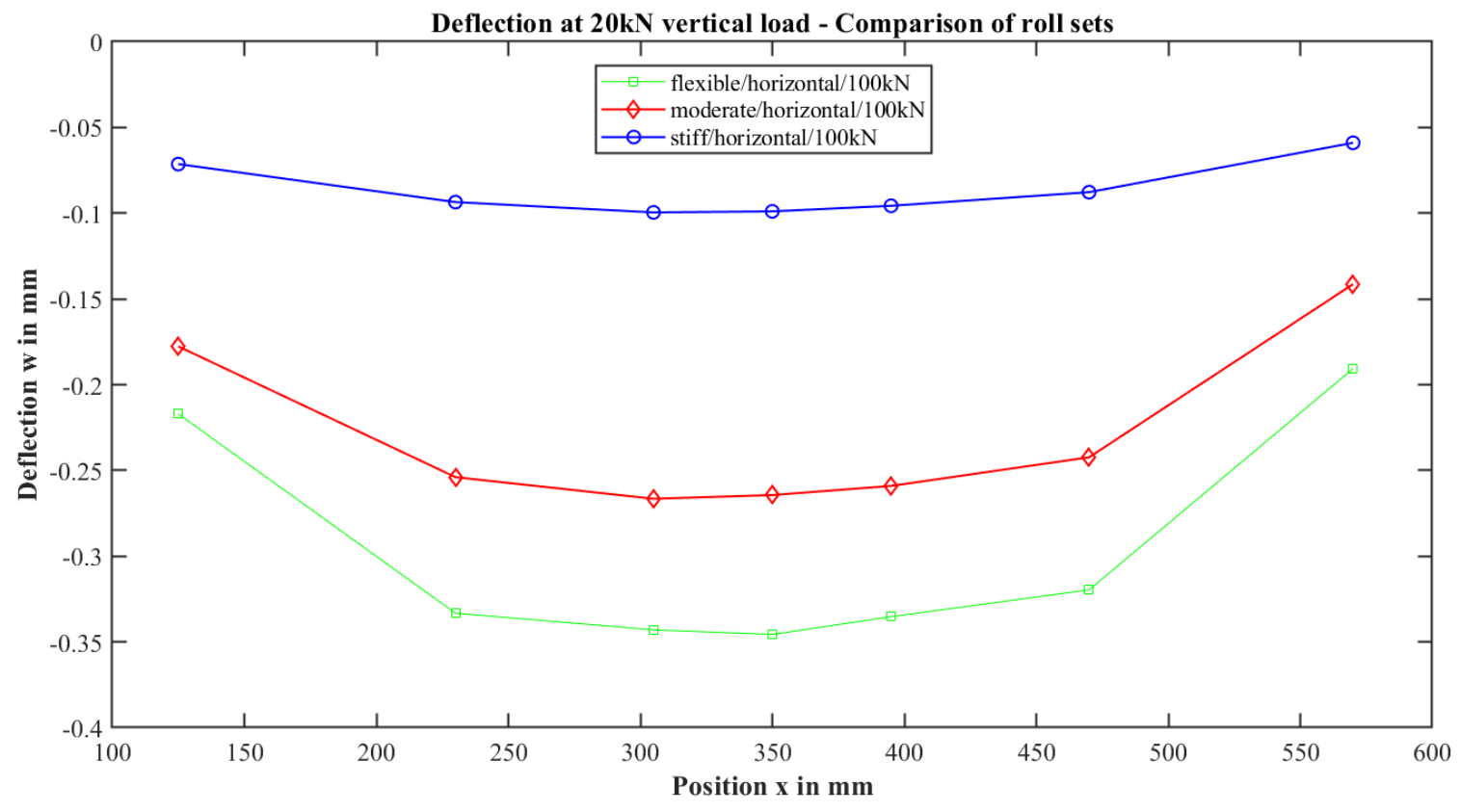

Fig. 3. Measured deflections at $20 \mathrm{kN}$ load - Variation of roll sets 
Figure 3 shows the differences in the deflections caused by variation of the roll sets. The flexible roll set shows a more substantial deflection than the stiff roll set, at the same load and a preload level of $100 \mathrm{kN}$. This behaviour can also be observed for all other preload and load levels. This indicates a significant influence of the used roll set on the occurring deflections of the rolls when a load is induced. The next varied parameter is the axial preload. Fig. 4 shows that increased axial preloads result in a decrease of the deflections of the tools. Additionally, at high preload levels, a small change in preload results in a small absolute change of the observed deflections.

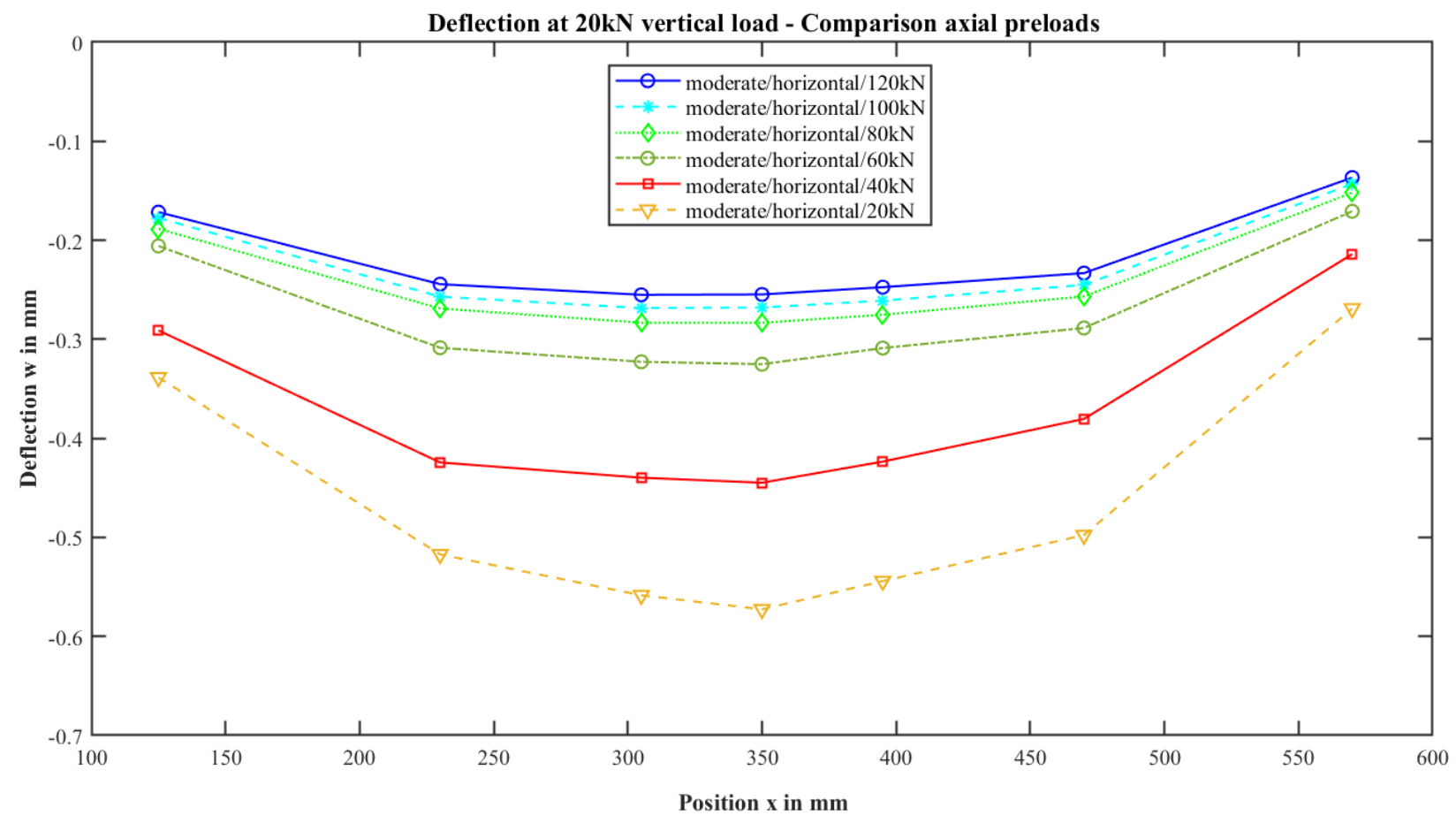

Fig. 4. Measured deflections and forces - Variation of axial preloads

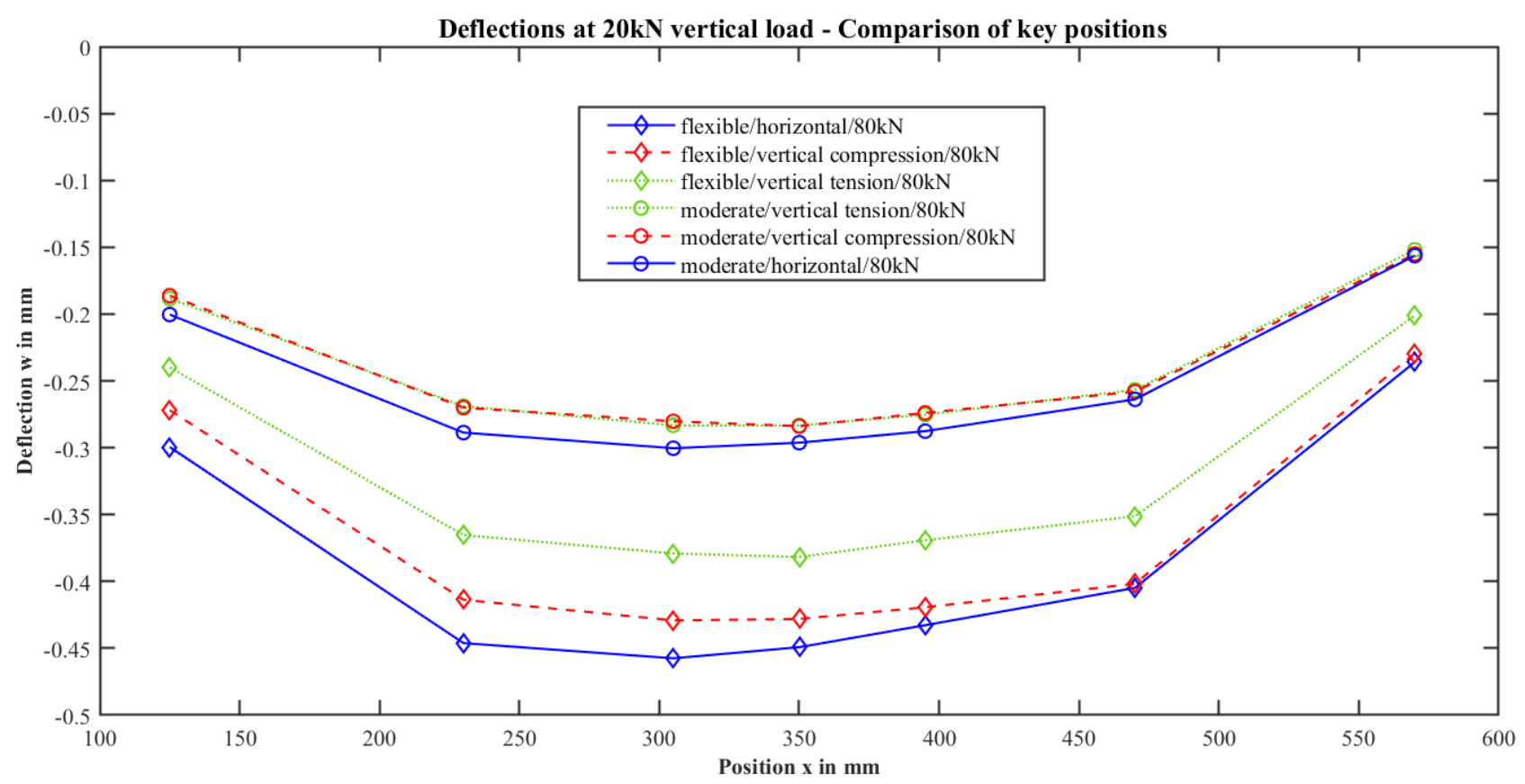

Fig. 5. Measured deflections at $20 \mathrm{kN}$ load - Variation of key positions

The third variation parameter -the key position- shows blurred behaviour. A difference can be observed in the deflections of the different key positions when all other parameters are held constant (Fig. 5). According to Figure 5, a definite impact of the feather key position, independent of the roll set, can not be derived. If the deflections for the different roll sets are compared, no explicit behaviour can be derived. 
The deflection data of the flexible roll set shows larger differences and different order over the variation of the key position than the data of the same experiments with the moderate roll set. This inconclusive behaviour can be observed in some data sets. Thus, an overall tendency to increasing deflections by the order of "VT", "VC", "H" can be seen for a majority of the collected data. The slightly asymmetrical behaviour of the deflections can be explained by an asymmetrical supporting of the shaft.

Figure 6 presents a comparison of the behaviour of the flexible and stiff roll set with different axial preloads. The abscissa represents the occurring deflection of a point on a roll at $\mathrm{x}=350 \mathrm{~mm}$. This point is exactly in the middle of the roll sets. The actual load on the rolls during the experiment is plotted on the ordinate. The lines represent the deflection of the middle of the roll sets when the force is gradually increased. The deflection at this point has been identified as a characteristic to clearly compare different measurements.

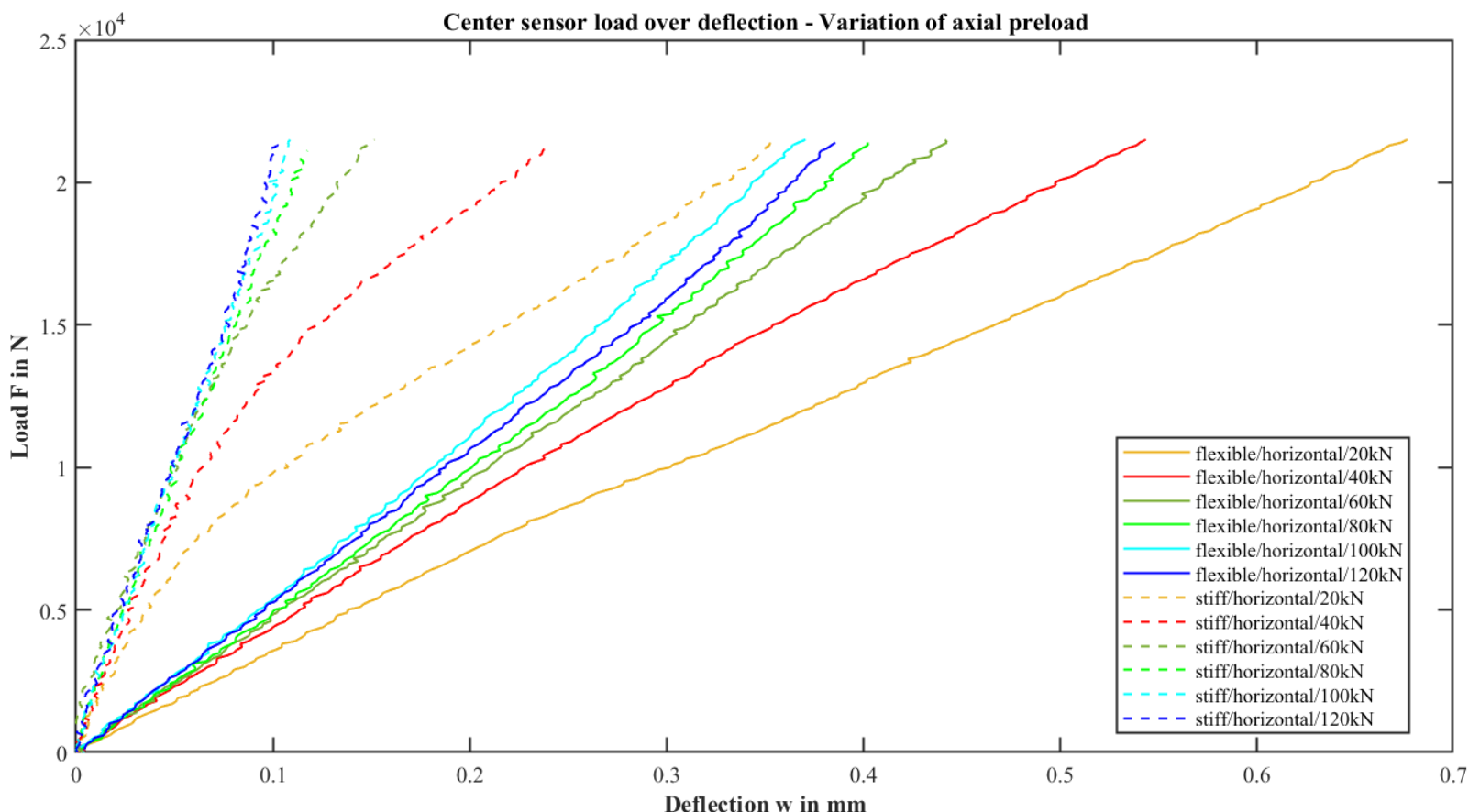

Fig. 6. Measured deflections with increasing load - Variation of axial preload

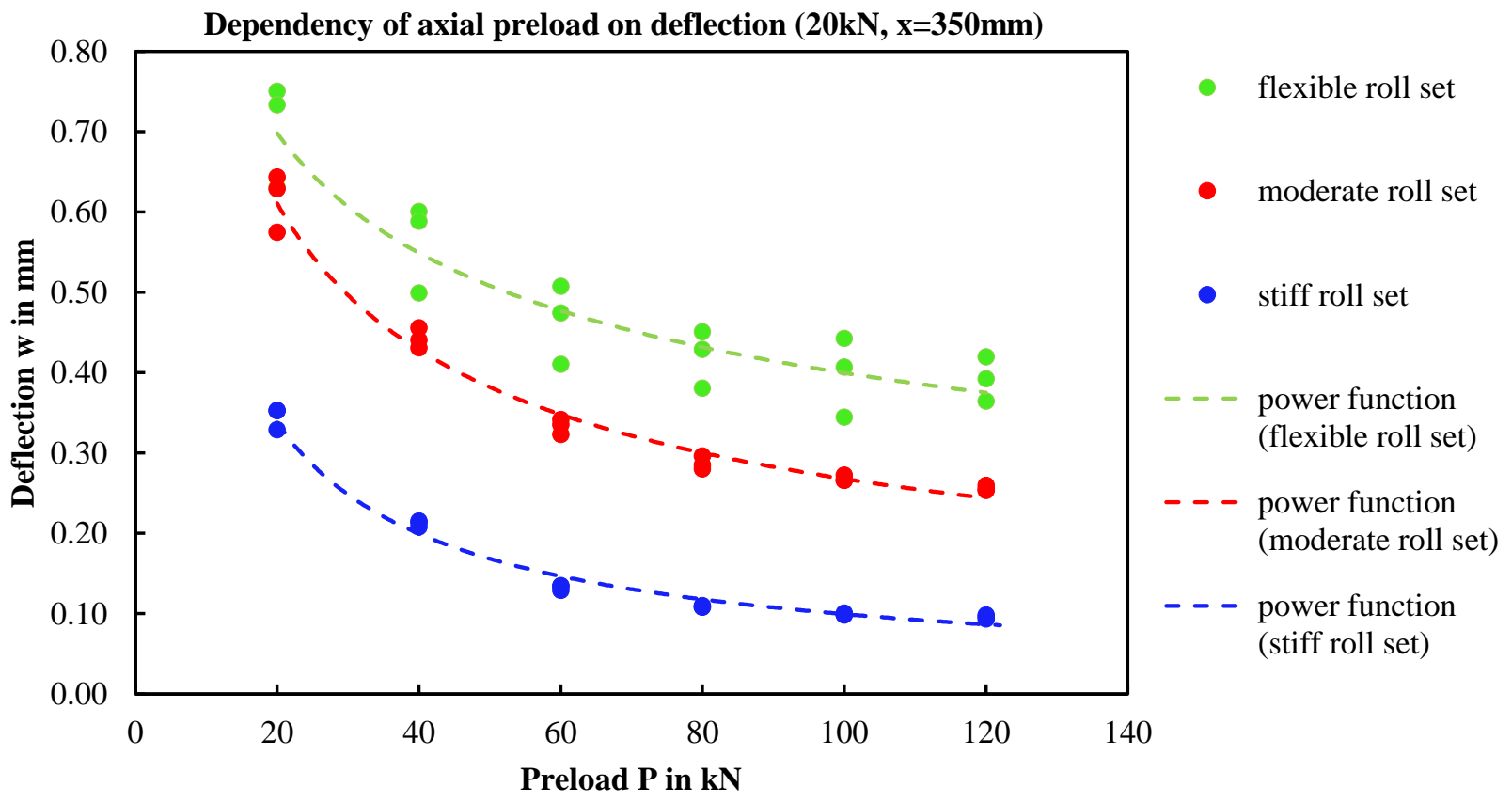

Fig. 7. Dependency of axial preload on deflections at $20 \mathrm{kN}$ load and at position $\mathrm{x}=350 \mathrm{~mm}$ 
In the measured range of the load, curves with higher preload levels tend to show almost directly proportional relation between deflection and induced load. Curves of experiments with lower preload behave differently. The stiff roll set shows a much more non-linear behaviour over all preload levels than the flexible roll set. This trend can also be observed for the moderate roll set (not plotted in Fig. 6). The following hypothesis is established to explain this behaviour: The stiff roll set consists of few individual rolls with big lengths and diameters compared to the other roll sets. These circumstances force the rolls to tilt more relative to each other with rising induced loads. This tilting is suppressed by high preloads and therefore occurs at higher load levels when the preload is increased. This effect leads to nonlinear behaviour in the deflection-load plots. The maximum deflection of a point on the rolls centred in the middle of the forming pass, vertically loaded with $20 \mathrm{kN}$, is used as the target value for the following regression model. This point seems to be a proper characteristic for the compliance of the setups.

Figure 7 depicts an obviously nonlinear dependency of the axial preloads on the measured deflection at $20 \mathrm{kN}$ vertical load and $x=350 \mathrm{~mm}$. It shows the same tendency which can be also seen at Fig. 4 where equidistant steps in preload show no equidistant steps in the generated deflection. Therefore, a linear regression cannot model the data properly. This nonlinearity is modelled by a power function for the individual roll sets in the regression model. The collected data is used to build up regression models to derive whether if the used parameters are sufficient to describe the deflection of such a setup or not.

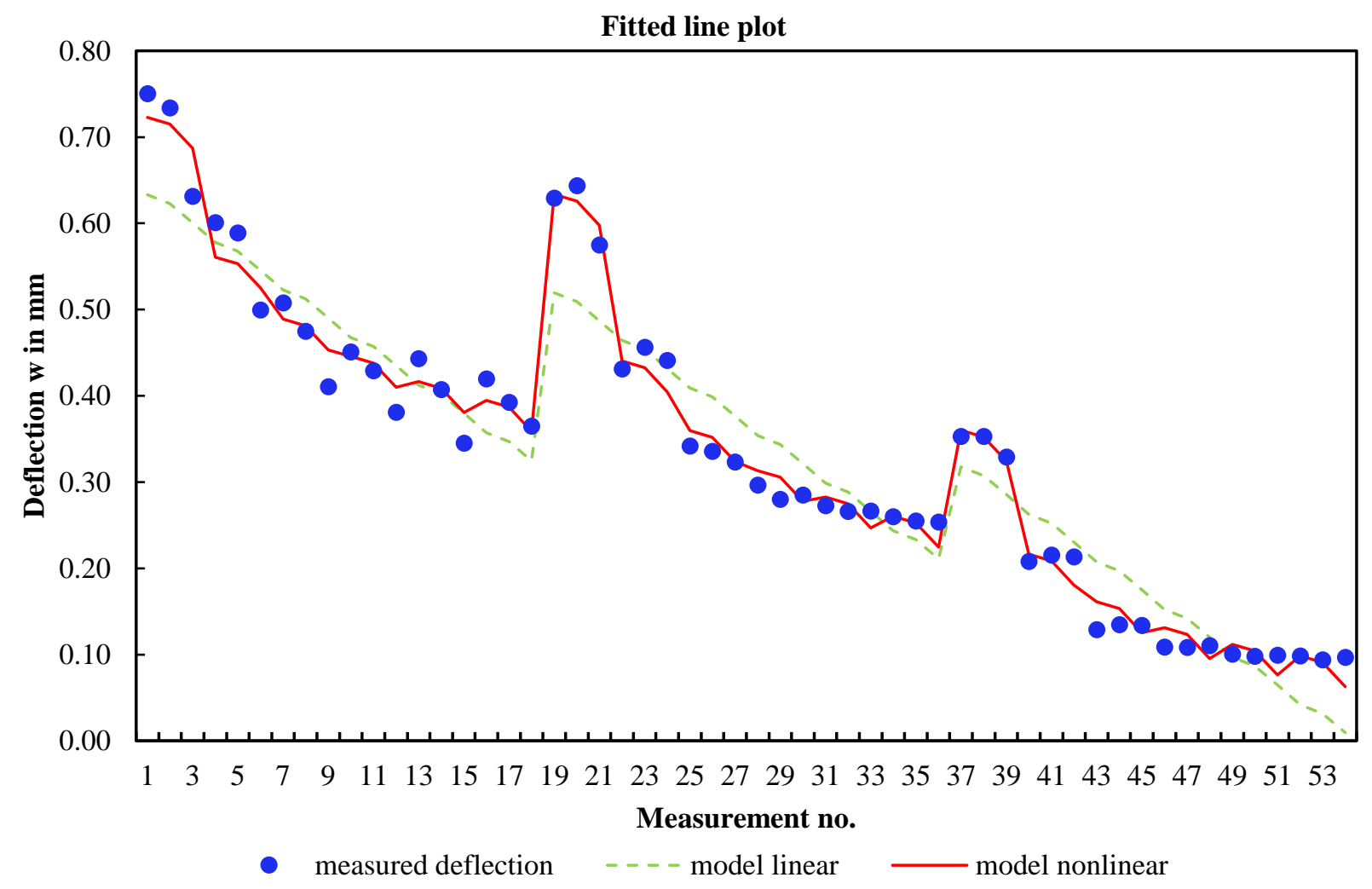

Fig. 8. Comparison of all Observations and the found models

Figure 8 presents the difference of the regression models compared to the measured data. For purposes of presentation the abscissa contains the numbers of the measurement ordered by roll set (1-18: flexible, 19-36: moderate, 37-54: stiff), by axial preload in ascending order and by the realised key positions (VT, VC, H). The found nonlinear model matches the measured data satisfactorily.

The found function is:

$$
\begin{gathered}
w=\text { flex } \cdot 2.454 \cdot \text { preload }^{-0.494}+\text { moderate } \cdot 3.450 \cdot \text { preload }^{-0.604}+\text { stiff } \\
\cdot 3.402 \cdot \text { preload }^{-0.757}+0.156 \cdot \text { flex }^{2} 0.062 \cdot \text { moderate } \\
-0.028 \cdot H+0.008 \cdot V T
\end{gathered}
$$

The variables "flex", "moderate", "stiff", "H" and "VT" in equation (1) are boolean values for the considered test setup. Where the first three variables represent the roll set and the others are used to consider the key position. The numbers were rounded to three decimal places. The influence of the key position is rather blurred. Especially for the flexible roll set, the key positions seem to show a non-negligible influence on the deflections (see Fig.8). 
This effect can be observed in Fig. 8 in measurement 9 to 18. In this section of the measurements, the variation of the key position adds scatter to the data. The other roll sets do not show this behaviour in the same intensity. Further measurements are necessary to determine the impact of the key position in a more detailed way. It is possible that the effect of the key position is superimposed by other unknown effects.

\section{Conclusions}

This study sheds light on the main impact factors on the observed deflections. Obviously, the roll set and the axial preload show a major impact. The key position turned out to be less significant or even inconclusive. The axial preload needs to be kept at defined levels to ensure reproducible behaviour of the setup under induced load. It can also be seen that the stiffness of the assembly increases with higher preloads. In the investigated load level spectrum, the deformation and the loads show a nearly linear relationship at higher axial preloads. Thus, limiting the preload to high levels will facilitate the creation of a simple model for the behaviour of the whole setup. Additionally, it guarantees reduced scatter in the mechanical characteristics of the reassembled forming passes.

The influence of the key position or other yet unknown influence factors should be investigated in further studies. More data of different roll sets should be collected to expand knowledge of the behaviour of the setup. To clarify the thesis about the tilting of the rolls, a FE-model may be used for validation. The collected data also serves as a basis for validations of simulation models of the deflection of the rolls. With these simulation models, the goal of compensating in-process deflections in the setup process offside the production plant to decrease fine adjustment times and scrap production on the production plant may be realised.

The applied regression model shows that information about the roll set, the axial preload and the load level are containing enough information to build up models for the deflection behaviour of such a roll forming mill. The model may be expanded to additionally collected data for other roll sets and other load levels besides 20kN. Further investigations need to be done on how the information of the roll set can be broken down to a few parameters derived from roll set geometry to reliably determine the load deflection behaviour even for roll sets of unknown mechanical characteristics.

\section{References}

[1] Halmos, F. (2006). Roll forming handbook, Taylor \& Francis, ISBN: 9780824795634, Toronto

[2] Traub, T.; Miks, C. \& Groche, P. (2017). Force Measurements Supporting the Set-up Process in Roll Forming, Athens: ATINER'S Conference Paper Series, No: MEC2017-2346

[3] Müller, C. (2014). Numerische Abbildung und Validierung von Beanspruchungsgrößen in Rollprofilierprozessen, Ph.D. Dissertation, Institut für Produktionstechnik und Umformmaschinen, TU Darmstadt, Darmstadt, Germany

[4] Sáenz de Argandoña, E.; Larrañaga, J.; Legarda, A.; \& Galdos, L. (2012). Roll Forming Set-Up Influence in the Forming Forces and Profile Quality, Key Engineering Materials, Bd. 504-506, S. 1249-1254

[5] Ferreira, P. (2016). Roll Forming - a study on machine deflection by means of experimental analysis and numerical developments, Faculty of Engineering, University of Porto

[6] Sanchez-Marin, F.; Roda-Casanova, V. \& Porras-Vazquez A. (2018). A new analytical model to predict the transversal deflection under load of stepped shafts, International Journal of Mechanical Sciences, Bd. 146-147, S. 91-104

[7] Radi, E.; Lanzoni, L.; Strozzi, A. \& Bertocchi, E. (2017). Shaft-hub press fit subjected to bending couples: Analytical evaluation of the shaft-hub detachment couple, Applied Mathematical Modelling, Bd. 50, S. 135-160

[8] Gotlih, J.; Karner, T.; Gotlih, K. \& Brezocnik, M. (2018). Experiment Based Structural Stiffness Calibration of a Virtual Robot Model, DAAAM International Scientific Book, 1. Aufl., Bd. 17, B. Katalinic, Hrsg. DAAAM International Vienna, S. 131-140

[9] Lamprecht M., Kocbay E., Leonhartsberger M., Vetyukov Y., \& F. Bleicher, (2020), Nonlinear mechanical model of the shaft of a roll forming mill and parameter identification, International Journal of Advanced Manufacturing Technology, unpublished

[10] Leonhartsberger M. (2018), Verformungsanalyse von Walzprofiliergerüsten - Reproduzierbare Gerüsteinstellung, Master thesis, Institute of Production Engineering and Photonic Technologies, TU Vienna, Vienna, Austria 